\title{
COMUNICAÇÃO
}

\section{DIFERENÇAS NA INTENSIDADE E NA EXPANSÃO DA PÚSTULA DA FERRUGEM DO CAFEEIRO EM DOIS ACESSOS DE Hemileia vastatrix}

\author{
Differences in the intensity and pustule expansion of coffee \\ rust for two Hemileia vastatrix accesses
}

\author{
Maria Eloisa Salustiano', Edson Ampélio Pozza², Antonio Carlos Ferraz Filho
}

\begin{abstract}
RESUMO
Objetivou-se, neste trabalho, estudar, em ambiente controlado, as diferenças na intensidade de doenças e na expansão da pústula de dois acessos de Hemileia vastatrix, coletados em plantas da cultivar Catuai das cidades de Coromandel (COR2), no Alto Paranaíba e de Ijaci (IIJ1), no Sul de Minas Gerais. As plantas inoculadas foram submetidas a três temperaturas $\left(15,20\right.$ e $\left.25^{\circ} \mathrm{C}\right)$ e três períodos de molhamento foliar (24, 48 e 72 horas de molhamento foliar), em esquema fatorial com três repetições. Ambos os acessos apresentaram maior severidade da doença quando submetidos a 24 horas de molhamento foliar, após a inoculação. A maior freqüência de infecção do IIJ1 foi a $15^{\circ} \mathrm{C}$, no entanto, a temperatura não influenciou essa variável para COR2. Houve maior severidade da ferrugem em COR 2 a $25^{\circ} \mathrm{C}$. A maior expansão da pústula, em folhas inoculadas com IIJ1, foi a $15^{\circ} \mathrm{C} \mathrm{com} 7,59 \mathrm{~cm}^{2}$, e a menor a $25^{\circ} \mathrm{C}$, com $5,37 \mathrm{~cm}^{2}$, enquanto para COR2 houve aumento à medida que se elevou a temperatura de 15 para $25^{\circ} \mathrm{C}$, de 1,44 para $6,62 \mathrm{~cm}^{2}$, respectivamente. Accessos provenientes de Ijaci e de Coromandel apresentaram diferenças na intensidade da ferrugem e na expansão das pústulas em ambiente controlado.
\end{abstract}

Termos para indexação: Variabilidade entre acessos, Coffea arabica, fatores ambientais, expansão da lesão.

\section{ABSTRACT}

The aim of this work was to study, under controlled environment, the differences in the disease intensity and pustule expansion of two Hemileia vastatrix accesses, sampled in cultivar Catuai coffee (Coffea arabica L.) plants from Coromandel (COR2) and Ijaci (IIJ1), towns located respectively in the West and South of Minas Gerais State. The inoculated plants were submitted to three temperatures $\left(15,20\right.$ and $\left.25^{\circ} \mathrm{C}\right)$ and three leaf wetness durations $(24,48$ e and 72 hours) in a factorial scheme with three replicates. Both accesses presented a higher disease severity when submitted to $24 \mathrm{~h}$ leaf wetness duration after inoculation. The higher infection frequency for IIJ 1 was at $15^{\circ} \mathrm{C}$, while the temperature did not influence this variable for COR2. There was a higher severity for COR2 inoculated plants when incubated at $25^{\circ} \mathrm{C}$. The higher pustule expansion, for leaves inoculated with IIJ1 was at $15^{\circ} \mathrm{C}$ with $7.59 \mathrm{~cm}^{2}$ and a lower at $25^{\circ} \mathrm{C}$, with $5.37 \mathrm{~cm}^{2}$, while for COR2 when temperature raised from 15 to $25^{\circ} \mathrm{C}$, there was an increase in the pustule expansion from 1.44 to $6.62 \mathrm{~cm}^{2}$, respectively. Fungal lines from Ijaci and from Coromandel presented differences in the intensity and pustule expansion of rust, under controlled environment

Index terms: Variability between fungal lines, Coffea arabica, environment factors, lesion expansion.

(Recebido em 21 de maio de 2007 e aprovado em 6 de maio de 2008)

A temperatura, a variedade do hospedeiro e a raça do patógeno foram os fatores que mais influenciaram os períodos de infecção e de geração da ferrugem do cafeeiro (FIGUEREDO et al., 1977; KUSHALAPPA \& MARTINS, 1984; MORAES et al., 1976; RAYNER, 1972). Contudo a temperatura foi considerada, por esses autores, como o fator mais importante. Notadamente, Moraes et al. (1976) concluíram que a variação nas temperaturas das regiões de Campinas, Monte Alegre do Sul e Pindorama no estado de São Paulo foram as responsáveis por alterar o período de incubação de Hemileia vastatrix Berk. \& Br. Diante disso, desenvolveram-se equações lineares para descrever o período de incubação (AKUTSU, 1981; MORAES et al., 1976; RAYNER, 1972), baseando-se nos valores máximo e mínimo das temperaturas prevalentes, durante o período de infecção. De acordo com esses autores, temperaturas elevadas reduziram o período de incubação de $H$. vastatrix, enquanto que temperaturas baixas prolongaram esse período.

\footnotetext{
'Doutora em Fitopatologia - Departamento de Fitopatologia/DFP - Universidade Federal de Lavras/UFLA - Cx. P. 3037 - $37200-000$ -

Lavras, MG - msalustiano@yahoo.com.br, biotita19@gmail.com - Bolsista do CNPq

2Doutor em Fitopatologia, Professor Adjunto - Departamento de Fitopatologia/DFP - Universidade Federal de Lavras/UFLA - Cx. P. 3037 - $37200-000$ Lavras, MG - eapozza@ufla.br - Bolsista do CNPq

${ }^{3}$ Engenheiro Florestal - Departamento de Ciências Florestais/DCF - Universidade Federal de Lavras/UFLA - Cx. P. 3037 - $37200-000$ - Lavras, MG acferraz@gmail.com.br - Bolsista do CNPq
} 
Dessa forma, as diferentes temperaturas e a umidade relativa de cada região produtora de café do Brasil podem estar influenciando os parâmetros monocíclicos da epidemia devido à adaptabilidade de populações do patógeno a essas condições climáticas, em maior ou menor escala.

O propósito deste trabalho foi estudar, em ambiente controlado, as diferenças na intensidade e na expansão da pústula de dois acessos de $H$. vastatrix, coletados nos municípios de Coromandel e de Ijaci em Minas Gerais.

Experimentos foram realizados, em câmara de crescimento de plantas, utilizando-se dois acessos de $H$. vastatrix coletados em áreas cafeicultoras dos municípios de Coromandel (COR2), na região do Alto Paranaíba e Ijaci (IIJ1), no sul de Minas, com temperaturas médias máximas de 27 e $24^{\circ} \mathrm{C}$ e mínimas de 16 e $14^{\circ} \mathrm{C}$ respectivamente (BRASIL, 2006; OLIVEIRA, 2005). Os acessos de $H$. vastatrix foram coletados em cafeeiros da cultivar Catuaí, retirando-se os urediniósporos com cápsula de gelatina tamanho 00 e, $\operatorname{logo}$ em seguida, peneirados a 100 mesh. A viabilidade dos urediniósporos foi preservada segundo técnica descrita por Zambolim et al. (2002).

Os acessos foram multiplicados em plantas da cultivar Catuaí, com três meses de idade. Foram inoculadas seis plantas de cafeeiro com cada acesso, com suspensão contendo $0,5 \mathrm{mg} / \mathrm{mL}$ de urediniósporos de $H$. vastatrix, com $0,05 \%$ de tween 80. Após a inoculação com micropulverizador, as plantas foram colocadas em câmara úmida, utilizando-se sacos plásticos escuros, durante 72 horas, a $20^{\circ} \mathrm{C}$ e $70 \%$ de umidade relativa e fotoperíodo de 12 horas. Após esse período, retirou-se a câmara úmida e as plantas permaneceram no mesmo ambiente até a produção de novos urediniósporos.

Para cada acesso, conduziu-se um experimento em esquema fatorial $3 \times 3$, com três temperaturas $\left(15,20\right.$ e $\left.25^{\circ} \mathrm{C}\right)$ e três períodos de molhamento foliar (24, 48 e 72 horas) e delineamento inteiramente ao acaso com três repetições. Em cada parcela, três plantas de cafeeiro com três meses de idade foram inoculadas com suspensão de urediniósporos na mesma concentração citada anteriormente. Após a inoculação, as plantas foram transferidas para as câmaras e protegidas com sacos plásticos preto por 24, 48 e 72 horas para constituírem câmara úmida. Ao final de cada período, os sacos plásticos foram retirados e as plantas mantidas nas mesmas temperaturas, com fotoperíodo de 12 horas. Todas as avaliações foram realizadas em um par de folhas expandidas de cada uma das três plantas de cada parcela.

A frequiência de infecção foi estimada semanalmente, utilizando-se o número de pústulas produzidas por unidade de área, a partir da inoculação. A severidade da ferrugem foi avaliada no final do experimento, medindo-se as áreas das folhas e das pústulas nelas contidas. Essas folhas e pústulas foram fotografadas com câmara digital, na face abaxial de cada folha, para posterior cálculo da área lesionada. As imagens digitalizadas foram utilizadas para mensurar a área, utilizando-se o programa Image Tool da Uthsca (University of Texas, San Antonio). Cada imagem digital gravada no formato JPEG foi padronizada em 4,0 x 4,0 cm e os valores das áreas organizados no programa Excel.

Para avaliar a expansão da pústula da ferrugem conduziu-se experimento em esquema de parcela subdividida com três temperaturas $\left(15,20\right.$ e $\left.25^{\circ} \mathrm{C}\right)$ nas parcelas e seis tempos $(0,7,14,21,28$ e 35 dias $)$ e sete repetições, sendo uma planta por repetição. Plantas de cafeeiro de três meses de idade foram inoculadas com suspensão de urediniósporos, na concentração citada anteriormente e submetidas à câmara úmida escura, por 24 horas, nas temperaturas de 15,20 e $25^{\circ} \mathrm{C}$. Após a retirada da câmara úmida, as plantas foram mantidas sob as mesmas temperaturas, com fotoperíodo de 12 horas. Com o surgimento dos primeiros sintomas, sete pústulas com sintomas "fecks", sendo uma pústula por folha não destacada, foram marcadas aleatoriamente e fotografadas durante seis semanas, com câmara digital. As imagens digitalizadas foram processadas utilizando-se a mesma metodologia citada anteriormente.

As análises estatísticas foram realizadas utilizandose o PROC GLM, do programa SAS Institute (2000). Os valores de severidade e expansão da lesão foram transformados em $\operatorname{arcos} e n \sqrt{x / 100}$ e $\log _{10}(\mathrm{x}+1,0)$, respectivamente e submetidos aos testes de Shapiro-Wilk e de Hartley e apresentaram normalidade e homogeneidade de variância. Os valores de freqüência de infecção apresentaram distribuição normal dos erros. As médias dos tratamentos foram comparadas pelo teste Tukey, a $5 \%$ de probabilidade.

Houve interação significativa entre a temperatura e o período de molhamento foliar, apenas para a frequiência de infecção em plantas inoculadas com IIJ1. A maior freqüência de infecção em plantas inoculadas com o acesso IIJ1 $\left(0,84\right.$ pústulas $\left./ \mathrm{cm}^{2}\right)$ ocorreu a $15^{\circ} \mathrm{C}$, com 24 horas de molhamento foliar (Tabela 1).

A menor temperatura e o menor período de umidade favoreceram esse acesso. Na região de Ijaci, as temperaturas médias mínimas registradas nos últimos anos estiveram em torno de $14^{\circ} \mathrm{C}$ (OLIVEIRA, 2005) e isso pode ter contribuído para a adaptabilidade desse acesso a temperaturas baixas. Portanto, à medida que se elevou a 
temperatura e a umidade, houve redução na freqüência de infecção. Por outro lado, não houve interação entre a temperatura e o molhamento foliar para plantas inoculadas com COR2. A maior freqüência de infecção em plantas inoculadas com COR2 ocorreu com 24 horas de duração do molhamento foliar, com 0,30 pústulas $/ \mathrm{cm}^{2}$ (Tabela 2).

Tabela 1 - Freqüência de infecção de plantas inoculadas com o acesso IIJ1 de Hemileia vastatix na cultivar Catuai, em três temperaturas e três períodos de molhamento foliar.

\begin{tabular}{|c|c|c|c|}
\hline \multirow{3}{*}{ Temperatura } & \multicolumn{3}{|c|}{ Freqüência de infecção (Pústulas/cm²) } \\
\hline & \multicolumn{3}{|c|}{ Períodos de molhamento foliar } \\
\hline & 24 & 48 & 72 \\
\hline 15 & $0,84 \mathrm{a} \quad \mathrm{A}$ & $0,54 \mathrm{a} \quad \mathrm{A}$ & 0,29 a $B$ \\
\hline 20 & $0,31 \mathrm{~b} \quad \mathrm{~A}$ & 0,17 a $\mathrm{A}$ & $0,22 \mathrm{a} \quad \mathrm{A}$ \\
\hline 25 & $0,13 \mathrm{~b} \quad \mathrm{~A}$ & 0,18 a $\mathrm{A}$ & 0,14 a $\mathrm{A}$ \\
\hline
\end{tabular}

Médias seguidas da mesma letra minúsculas nas colunas e maiúsculas nas linhas não diferem entre si, pelo teste Tukey $(\mathrm{P}>0,05)$

Tabela 2 - Influência do período de molhamento foliar na freqüência de infecção de Hemileia vastatrix e na severidade da ferrugem, na cultivar Catuai, inoculada com urediniósporos dos acessos COR2 e IIJ1.

\begin{tabular}{|c|c|c|c|}
\hline $\begin{array}{l}\text { Período de } \\
\text { Umidade } \\
\text { (horas) }\end{array}$ & $\begin{array}{c}\text { Freqüência } \\
\text { de infecção } \\
\text { Pústulas/cm² }\end{array}$ & \multicolumn{2}{|c|}{$\begin{array}{c}\text { Severidade } \\
(\%)\end{array}$} \\
\hline & COR2 & IIJ1 & COR2 \\
\hline 24 & $0,30 \mathrm{a}$ & $33,1 \mathrm{a}$ & $24,64 \mathrm{a}$ \\
\hline 48 & $0,14 \mathrm{~b}$ & $19,61 \mathrm{~b}$ & $10,19 \mathrm{~b}$ \\
\hline 72 & $0,02 \mathrm{~b}$ & $14,94 \mathrm{~b}$ & $5,20 \mathrm{~b}$ \\
\hline
\end{tabular}

Médias seguidas da mesma letra nas colunas não diferem entre si, pelo teste Tukey $(\mathrm{P}>0,05)$

Akutsu (1981) também encontrou a máxima freqüência de infecção de $H$. vastatrix após 24 horas de água livre sobre a superfície foliar, depois da inoculação.
Não houve interação entre a temperatura e o molhamento foliar em relação à freqüência de infecção de plantas inoculadas com COR2 e em relação à severidade, em plantas inoculadas com os dois acessos. As máximas severidades constatadas no período de molhamento foliar de 24 horas foram 33,14 e 24,64\%, para IIJ1 e COR2, respectivamente (Tabela 2). Com o aumento do período de molhamento para 48 horas, houve queda na severidade em mais de $60 \%$, em plantas desses acessos.

$\mathrm{O}$ efeito da temperatura foi significativo para expansão da pústula e severidade das plantas inoculadas com o acesso COR2, tendo os maiores valores de severidade $(24,73 \%)$ e tamanho médio das pústulas $(6,62$ $\mathrm{cm}^{2}$ ) constatados a $25^{\circ} \mathrm{C}$ (Tabela 3 ).

Não houve diferenças entre as temperaturas testadas para freqüência de infecção em plantas inoculadas com COR2. Com a redução da temperatura para 20 e $15^{\circ} \mathrm{C}$, houve queda de $49,8 \%$ e $88,2 \%$, respectivamente, na área lesionada com o acesso COR2. Em relação às plantas inoculadas com o acesso IIJ1, as temperaturas avaliadas influenciaram significativamente a expansão da pústula mas não a severidade (Tabela 3 ). O maior valor médio de tamanho da pústula, em plantas inoculadas com IIJ1 (7,59 $\mathrm{cm}^{2}$ ), foi constatado a $15^{\circ} \mathrm{C}$. Não houve correlação entre a temperatura e as variáveis avaliadas. Oliveira (2004) em seus estudos com infecção de Botyitis cinerea Pers., em hastes de Hibiscus sabdariffa L., também concluiu que houve maior incidência e severidade das secas das hastes, quando plantas inoculadas com $B$. cinerea foram mantidas a $15^{\circ} \mathrm{C}$, associado à duração do molhamento foliar de 24 horas.

Enquanto os maiores valores de área da pústula expandida de plantas inoculadas com IIJ1 foi a $15^{\circ} \mathrm{C}(7,59$ $\left.\mathrm{cm}^{2}\right)$, o de plantas inoculadas com COR2 foi a $25^{\circ} \mathrm{C}(6,62$ $\mathrm{cm}^{2}$ ). Para plantas inoculadas com o acesso COR2, quando a temperatura aumentou de 15 para $25^{\circ} \mathrm{C}$, o tamanho médio das pústulas aumentou em 4,5 vezes, de 1,44 para $6,62 \mathrm{~cm}^{2}$. $\mathrm{Na}$ região de Coromandel, as médias das temperaturas

Tabela 3 - Influência da temperatura na freqüência de infecção de Hemileia vastatrix, na severidade e na expansão da ferrugem, na cultivar Catuai, inoculada com urediniósporos dos acessos COR2 e IIJ1.

\begin{tabular}{cccccc}
\hline Temperatura & $\begin{array}{c}\text { Freqüência de } \\
\text { infecção }\end{array}$ & Severidade & & Expansão da pústula \\
\hline$\left({ }^{\circ} \mathrm{C}\right)$ & Pústulas/cm ${ }^{2}$ & $(\%)$ & COR2 & COR2 & IIJ1 \\
\hline 15 & COR2 & IIJ1 & $2,92 \mathrm{~b}$ & $1,44 \mathrm{c}$ & $7,59 \mathrm{a}$ \\
20 & $0,13 \mathrm{a}$ & $23,47 \mathrm{a}$ & $12,42 \mathrm{~b}$ & $3,21 \mathrm{~b}$ & $7,45 \mathrm{~b}$ \\
25 & $0,15 \mathrm{a}$ & $22,86 \mathrm{a}$ & $6,62 \mathrm{a}$ & $5,37 \mathrm{~b}$ \\
\hline
\end{tabular}

Médias seguidas da mesma letra nas colunas não diferem entre si, pelo teste Tukey $(\mathrm{P}>0,05)$ 
máximas e mínimas, nos últimos cinco anos, foram de 27,4 e $16,7^{\circ} \mathrm{C}$, respectivamente (BRASIL, 2006). As pústulas das plantas inoculadas com o acesso COR2 expandiram em ampla faixa de temperatura, variação essa que, normalmente, ocorre na região com noites frias e dias muito quentes. Assim como na expansão da pústula de $H$. vastatrix, em outros patossistemas foi também avaliada a influência da temperatura na expansão da lesão (KUSHALAPPA \& ZULFIGAR, 2001; LUI \& KUSHALAPPA, 2002, 2003; MILLER et al., 2003; SUBBARAO \& MICHAILIDES, 1995).

Observou-se que o molhamento foliar de 24 horas foi o suficiente para causar infecção pelos dois acessos. Já a temperatura influenciou a expansão da pústula pelos dois acessos e a severidade do acesso COR2. No entanto, não foram observados efeitos diferenciadores na severidade de plantas inoculadas com o acesso de IIJ2, nas temperaturas testadas. Provavelmente, diferentes acessos podem exigir diferentes temperaturas para colonizar e expandir suas pústulas. Há, portanto, a necessidade de mais estudos com mais acessos de $H$. vastatrix, em diferentes condições ambientais, com intuito de respaldar as hipóteses aqui mencionadas.

\section{REFERÊNCIAS BIBLIOGRÁFICAS}

AKUTSU, M. Relações de funções climáticas e bióticas com a taxa de infecção da ferrugem do cafeeiro (Hemileia vastatrix Berk et Br.). 198167 f. Dissertação (Mestrado em Fitopatologia) - Universidade Federal de Viçosa, Viçosa, 1981.

BRASIL. Ministério da Agricultura Pecuária e Abastecimento. Agritempo: sistema de monitoramento agrometeorológico. Disponível em: <http:// 'WWW.agritempo.gov.brh

FIGUEIREDO, P.; MARIOTTO, P. R.; SILVEIRA, A. P.; GERALDO JUNIOR, C. Período de incubação, evolução de Hemileia vastatrix Berk. \& Br. e utilização da equação de Rayner em alguns municípios caffeeiros do Estado de São Paulo. O Biológico, São Paulo, v. 43, p. 32-40, 1977.

KUSHALAPPA, A. C.; MARTINS, C. P. Incubation and generation periods for Hemileia vastatrix on coffee in Viçosa, Minas Gerais. Fitopatologia Brasileira, Brasília, v. 5, n. 6, p. 177- 183, June 1984.
KUSHALAPPA, A. C.; ZULFIGAR, M. Effect of wet incubation time and temperature on infection, and of storage time and temperature on soft rot lesion expansion in potatoes inoculated with Erwinia carotovora ssp. carotovora. Potato Research, Wageningen, v. 44, n. 3, p. 233-242, Mar. 2001.

LUI, L. H.; KUSHALAPPA, A. C. Response surface models to predict potato tuber infection by Fusarium sambucinum from duration of wetness and temperature, and dry rot lesion expansion from storage time and temperature. International Journal of Food Microbiology, Amsterdam, v. 76, n. 1/2, p. 19-25, Jan./ Feb. 2002.

LUI, L. H.; KUSHALAPPA, A. C. Models to predict potato tuber infection by Pythium ultimum from duration of wetness and temperature, and leak-lesion expansion from storage duration and temperature.

Postharvest Biology and Technology, Amsterdam, v. 27, n. 3, p. 313-322, Mar. 2003.

MILLER, T. C.; GUBLER, W. D.; GENG, S.; RIZZO, D. M Effects of temperature and water vapor pressure on conidial germination and lesion expansion of Sphaerotheca macularis f. sp. fragariae. Plant Disease, Saint Paul, v. 87, n. 5, p. 484-492, May 2003.

MORAES, S. A.; SUGIMORIM, M. H.; FIBEIRO, I. J. A.; ORTOLANI, A. A.; PEDRO JUNIOR, M. J. Período de incubação de Hemileia vastatrix Berk. \& Br. em três regiões do Estado de São Paulo. Summa

Phytopathologica, Piracicaba, v. 2, n. 1, p. 32-38, fev. 1976.

OLIVEIRA, C. A. Epidemiologia e manejo da seca das hastes (Botrytis cinerea) em Hibiscus sabdariffa. 2004.

116 p. Tese (Doutorado em Fitopatologia) - Universidade Federal de Lavras, Lavras, 2004.

OLIVEIRA, F. A. Validação de modelos de previsão da ferrugem do cafeeiro e monitoramento de esporos de Hemileia vastatrix e Cercospora coffeicola em Lavras, MG. 2005. 98 p. Tese (Doutorado em Fitopatologia) - Universidade Federal de Lavras, Lavras, 2005.

RAYNER, R. W. Micologia y biologia de la roya del caferto. Turrialba: Instituto Interamericano de Ciências Agrícolas de la OEA, 1972. 175 p.

SAS INSTITUTE. The SAS system: version 8.1 for Windows. Cary, 2000. 
SUBBARAO, K. V.; MICHAILIDES, T. J. Effects of temperature on isolates of Fusarium moniliforme causing fig endossepsis and Aspergillus niger causing smut. Phytopathology, Saint Paul, v. 86, n. 6, p. 662- 668, June 1995.
ZAMBOLIM, L.; VALE, F. X. R.; PEREIRA, A. A.; COSTA, E.; PEREIRA, A. A.; CHAVES, G. M. Epidemiologia e controle integrado da ferrugem do cafeeiro. In: ZAMBOLIM, L. (Ed.). Estado da arte de tecnologias na produção de café. Viçosa: UFV, 2002. cap. 10, p. 369-450. 